\title{
FIELD-ASSISTED PHOTODESORPTION OF IONS FROM METAL AND SEMICONDUCTOR SURFACES
}

\author{
S. JAENICKE, A. CISZEWSKI (1), W. DRACHSEL, U. WEIGMANN (2) \\ T.T. TSONG( $\left.{ }^{3}\right)$, J.R. PITTS ${ }^{(4)}$, J.H. BLOCK and D. MENZEL* \\ Fritz-Haber-Institut der Max-Planck-Gesellschaft, \\ Faradayweg 4-6, D-1000 Berlin 33, F.R.G. \\ "Physics Department, Technical University of Munich, \\ D-8046 Garching, F.R.G.
}

Abstract - The influence of strong electric fields on the photon-stimulated desorption of small molecules from metal and silicon surfaces has been studied. With hydrogen only field adsorbed $\mathrm{H}_{2}$ as well as $\mathrm{H}_{3}$ are desorbed as singly charged ions. Chemisorbed atomic hydrogen obviously has a photo-ionization cross-section at metal surfaces which is too small to be detected. From clean and oxidized Si surfaces $\mathrm{H}^{+}$ as well as Si-containing hydrides and oxides are photodesorbed at field strengths as low as $6 \mathrm{~V} / \mathrm{nm}$. Field adsorption of water leads to whisker-like layers, from which $\mathrm{H}_{3} \mathrm{O}^{+} \cdot \mathrm{nH}_{2} \mathrm{O}$-clusters are photo-desorbed with rather high quantum yields. The desorption spectrum exhibits a sharp onset at a wave length of $165 \mathrm{~nm}$; the onset energy shifts with fecreasing field strength towards higher energies:

\section{INTRODUCTION}

The simultaneous interaction of a high electric field and of photons of suitable energy on an adsorbed molecule can lead to desorption of ionic species. Two fundamentally different mechanisms can be considered, which we will refer to as:

a. Photon-assisted field desorption. This mechanism has been brought forward by Tsong et al $11 /$; it assumes that the charge transfer from the adsorbate to the metal or semiconductor substrate proceeds via electron tunnelling from an excited state of the adsorbed molecule into an empty electron level of the solid.

b. Field-assisted photodesorption. Here ionizing the adsorbate is done by electronic excitation as in the field free case. The mechanism is similar to those discussed for electron-stimulated desorption by Redhead /2/, Menzel and Gomer /3/,

\footnotetext{
(1) On leave from Physical Department, University of Wroclaw, PL 50-205 Wroclaw, Poland

(2) Permanent address : Fraunhofer Institute for Microstructure Research, D-1000 Berlin 33, F.R.G.

(3) On sabbatical leave from Physics Department, Pennsylvania State University. University Park. PA 16802, U.S.A.

(4) Permanent address : Solar Energy Research Institute, Golden, CO., U.S.A.
} 
Antoniewicz /4/, Knotek and Feibelman /5/ and Gomer /6/. The electric field facilitates the removal of the ionized species from the surface and thus increases the escape probability. According to these mechanisms, the photon energy has always to be larger than the ionization potential of the adsorbate.

Previous experiments with tunable laser radiation in the visible and long-wavelength UV have shown that mechanism (a) could only be found, so far, for the case of ethylene on silver $/ 7 \%$. The aim of the present investigation is to elucidate which of the models, proposed under (a) or (b), describes the reaction in other systems.

\section{EXPERIMENTAL}

The apparatus used has been described elsewhere $/ 8 /$. In short, it consists of a field ion microscope, where the tip to screen distance also serves as the mass analyzer in the time-of-flight $(t-0-f)$ mode. Monochromatized synchrotron radiation (SR) was focussed onto the tip, and mass spectra of the desorbed ions were recorded, taking advantage of the puised structure of the SR light $(5 \mathrm{MHz}$ at BESSY, $1 \mathrm{MHz}$ at DORIS). The substrates were shaped in the form of field emitter tips by chemical etching and electropolishing, following established procedures /9/. Most of the gases used were Messer Griesheim pressure cans with a nominal purity > $99.99 \%$. Deutrium was supplied by Linde in a break seal flask. Water was triply-distilled and thoroughly degassed by several freeze-pump-thaw cycles. In order to separate the surface signal from the background, due to field ionization and photoionization in the gas phase, it is mandatory to work at pressures less than $2 * 10^{-9}$ mbar. Therefore a good background pressure is essential for meaningful results. A pressure of $<3 * 10^{-10}$ mbar was routinely achieved 12 hours after a light bakeout using a $330 \mathrm{l} / \mathrm{s}$ turbomolecular pump and a lq. $\mathrm{N}_{2}$. cooled Ti sublimation pump. The residual gas was analysed with a Balzers GMG 311 quadropole mass spectrometer and found to consist mainly of $\mathrm{H}_{2}$ and $\mathrm{CO}$ with traces of $\mathrm{H}_{2} \mathrm{O}$ and $\mathrm{CO}_{2}$. In order to avoid unwanted reactions on the hot filaments, gas composition and pressure measurements were only made after the photodesorption data had been taken.

\section{RESULTS}

Previous experiments with laser radiation /10/ had established in most of the studied systems that for photodesorption, light energies above the ionization energy are necessary. In this case, mechanisms involving electron tunneling can be excluded If the photon energy, which leads to desorption is comparable to the ionization energy of the adsorbate, the Menzel-Gomer-Redhead (MGR) model describes the desorption process most accurately. On the basis of this model, one expects a very pronounced mass dependence of the desorption rate. Specifically on the system $\mathrm{H}_{2} / \mathrm{W}(100)$ Jelend and MenzeI $/ 11 /$ found a $H / D$ isotope effect as big as 150 . We therefore investigated the deso ption yield of $\mathrm{H}^{+}$and $\mathrm{D}^{+}$ions from $\mathrm{W}$ and $\mathrm{Ni}$ surfaces with wideband radiation from $30-120 \mathrm{eV}$. Pure $\mathrm{H}_{2}$ and $\mathrm{H}_{2} / \mathrm{D}_{2}$ - mixtures (up to $60 \% \mathrm{H}_{2}$ from the re- 
sidual gas) were dosed onto the tip, and the desorbing ions recorded as a function of temperature and field strength. Within the uncertainty of our composition determination, no preferential adsorption or desorption could be found. This agrees well with another observation of Menzel, who found only a very small isotope effect for $\mathrm{H}_{2}^{+}$from $\mathrm{W}(100)$, contrasting the extreme isotope sensitivity for $\mathrm{H}^{+}$desorption. $\mathrm{H}_{2}^{+}$ thus is the primary species in field-assisted photo-desorption. This becomes apparent also in the field strength dependence of the $\mathrm{H}^{+}, \mathrm{H}_{2}^{+}$and $\mathrm{H}_{3}^{+}$desorption yield /12/. No stimulated desorption is observed below approx. $15 \mathrm{~V} / \mathrm{nm}$. At higher field strength when field adsorption of hydrogen molecules sets in, $\mathrm{H}_{2}^{+}$is detected. If one

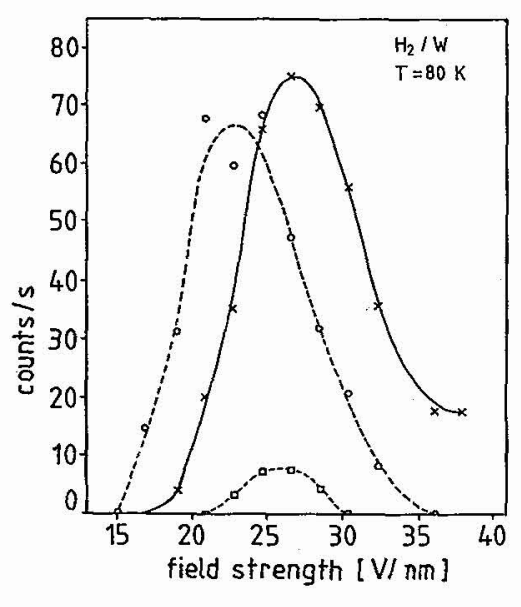
Fig. 1 - Ion yield for photostimulated desorption as a function of field strength

$$
\begin{aligned}
& \mathrm{x} \times \mathrm{X} \mathrm{H}^{+} \\
& \circ 00 \mathrm{H}_{2}{ }^{+} \\
& \text {ㅁ } \mathrm{H}_{3}{ }^{+}
\end{aligned}
$$
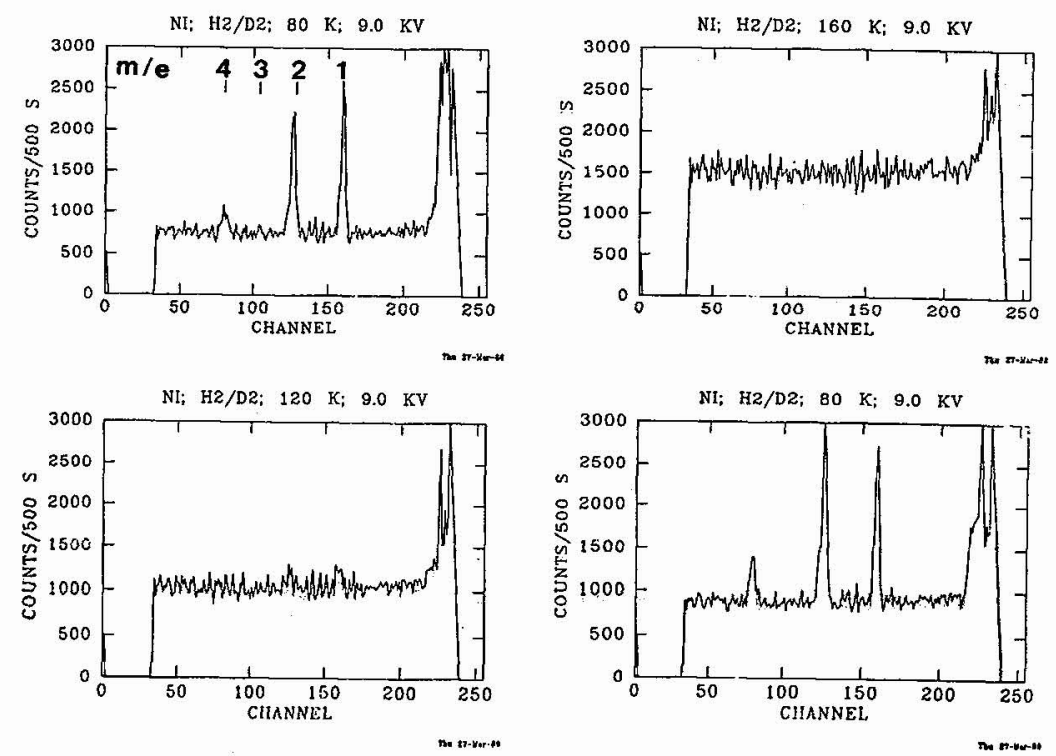

Fig. 2 - Temperature dependence of the desorption signals: $\mathrm{H}_{2} / \mathrm{D}_{2}$ from $\mathrm{Ni}$. Original traces; the peak on the right hand sight is due to stray light from the desorption pulse. 
increases the field strength further, the $\mathrm{H}^{+}$signal grows at the expence of the $\mathrm{H}_{2}^{+}$, presumably by field dissociation of the molecular ion. Neither on $\mathrm{W}$ nor on $\mathrm{Ni}$ did we find a detectable rate of isotope exchange at $80 \mathrm{~K}$. Increasing the temperature to $120 \mathrm{~K}$ virtually suppresses the desorption signal (Fig.2); upon cooling back to $80 \mathrm{~K}$, the composition of the desorbed species is almost identical to that at the beginning. On Ni, no mass 3 is detected, showing unambiquously that no HD has been formed. On $\mathrm{Si}$ and oxidized Si surfaces, larger signals were expected since reneutralization of the ions should be slower, due to the lower concentration of free electrons. Indeed, ca. 10 times more intense signals were recorded. Also, $\mathrm{H}^{+}$was found already at low field strength, and at room temperature. Obviously, a Si-H or SiO-H surface bond can be broken photolytically, leading to the desorption of $\mathrm{H}^{+}$. The $\mathrm{H}^{+}$-photodesorption threshold neàr $10 \mathrm{eV}$ could be verified by inserting a Lif-filter in the SR beam. Unfortunately, the monochromator used at BESSY had too low a photon flux in this range to establish the desorption threshold more clearly.

In the search for a system with higher desorption yield we succeeded with $\mathrm{H}_{2} \mathrm{O}$-layers grown on a field emitter in the strong electric field. In the photodesorption mass spectra, we observed protonated water clusters similar to those seen by Tsong and Liou /13/ and earlier by Beckey /14,15/ and Schmidt /16/. At high field, $\mathrm{H}_{3} \mathrm{O}^{\dot{+}}$ is the most abundant species. At low field, however, $\mathrm{H}_{3} \mathrm{O}^{+} \star_{2} \mathrm{H}_{2} \mathrm{O}$ is most frequently observed though clusters up to $\mathrm{H}_{3} \mathrm{O}^{+} * 16 \mathrm{H}_{2} \mathrm{O}$ are observed. All these clusters show a threshold at a wavelength near $165 \mathrm{~nm}$, suggesting a common excitation step for all the clusters. This confirms the model of water whiskers (Fig. 3), which was derived by Anway $/ 17 /$ on the basis of appearance energy measurements. Also, we want to point out that the observed desorption spectrum closely resembles the adsorption spectrum of liquid water $/ 18 /$ measured by Painter et al. at the triple point.

Financial support by the BMFT (Project No. 05242 GZP) is gratefully acknowledged. REFERENCES

11/ Tsong, T.T., Block, J.H., Nagasaka, M. and Viswanathan, B., J. Chem. Phys.., 65 (1976) 2469.

/2/ Redhead, P.A., Can. J. Phys., 42 (1964) 886.

13/ Menzel, D. and Gomer, R., J. Chem. Phys., 41 (1964) 3311.

/4/ Antoniewicz, P.R., Phys. Rev., B21 (1980) 3811.

15/ Knotek, M.L. and Feibelman, P.J., Phys. Rev. Lett., 40 (1978) 964.

16/ Gomer, R. in: Desorption Induced by Electronic Transitions DIET I, N.H. Tolk, M.M. Traum, J.C. Tully and T.E. Madey (eds.), Springer Heidelberg, New York, 1983 , p. 40.

/7/ Nishigaki, S., Drachel, W. and Block, J.H., Surface Science, 87 (1979) 389

/8/ Drachsel, W., Weigmann, U., Jaenicke, S. and Block, J.H. in: Desorption Induced by Electronic Transitions DIET II, W. Brenig and D. Menzel (eds.), Springer Series in Surface Science, Vol. 4, Springer Verlag Heidelberg, 1985, p. 245 
a

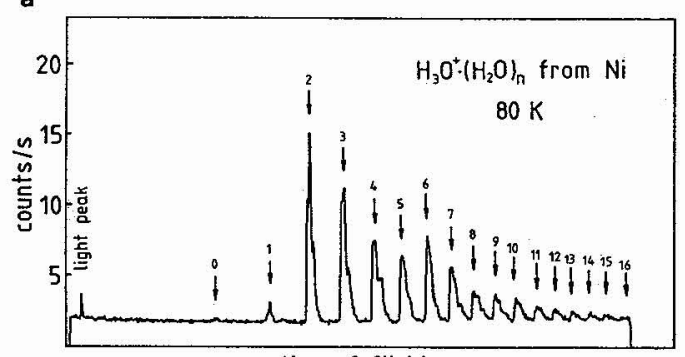

time of flight

c

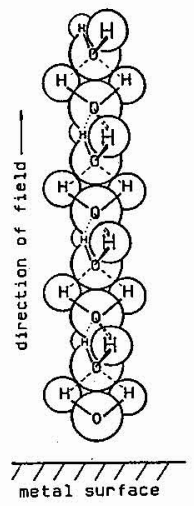

b

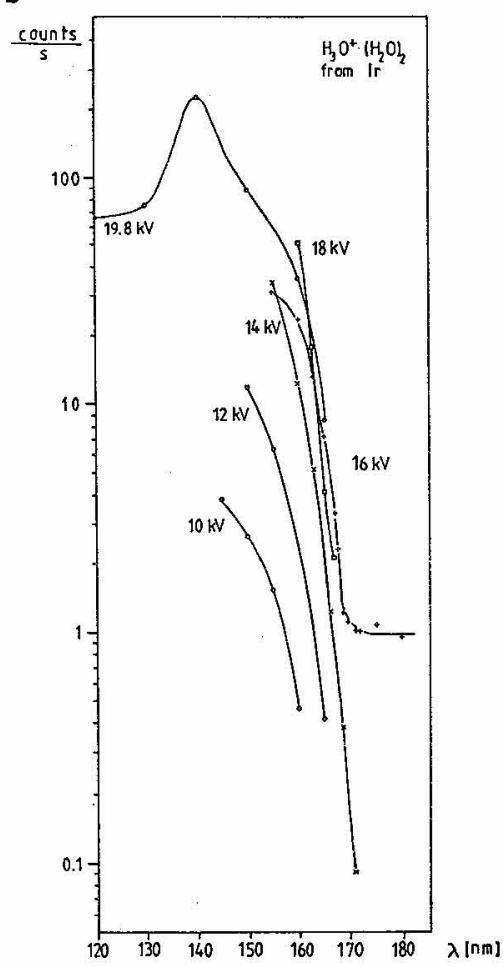

Fig. 3 - Field-assisted photodesorption from condensed water films

a) ToF mass spectrum for the various species desorbing from $\mathrm{H}_{2} \mathrm{O}$ on $\mathrm{Ni}$ $\mathrm{T}=80 \mathrm{~K}, \mathrm{P}_{\mathrm{H}_{2} \mathrm{C}}=5.6 \times 10^{-9}$ mbar.

b) desorption yield vs. wavelength of the excitation light at various applied fields (substrate iridium).

c) proposed model of a "water whisker" growing in an electric field.

19/ Miiller, E.W. and Tsong, T.T. Field Ion Microscopy - Principles and Application, Elsevier Publishing Company, New York, 1969.

/10/ Drachsel, W., Block, J.H. and Viswanathan, B., in: Surface Studies with Lasers, Springer Series in Chemical Physics, 33, eds. F.R. Aussenegg, A. Leitner,

M.E. Lippitsch, Springer Verlag Berlin-Heidelberg, 1985, p. 221

/11/ Jelend, w. and Menzel, D., Chem. Phys. Lett., 21 (1973) 178.

112/ Weigmann, U., Jaenicke, St., Pitts, R., Drachsel, W., and Block, J.H., Journal de Physique, 47 (1986) C2-145.

/13/ Tsong, T.T. and Liou, Y., Phys. Rev., B 32 (1985) 4340.

/14/ Beckey, H.D., Z. Naturforsch., A, 14 (1959) 712. 
/15/ Beckey, H.D., Z. Naturforsch., A, 15 (1960) 822 .

/16/ Schmidt, W.A., Z. Naturforsch., A, 19 (1964) 318.

/17/ Anway, A.R., J. Chem. Phys., 50 (1969) 2012.

/18/ Painter, L.R., Birkhoff, R.D. and Arakawa, E.T., J. Chem. Phys. 51 (1969) 243 